\title{
EU mobility partnerships: a smart instrument for the externalization of migration control
}

\author{
Stefan Brocza ${ }^{1} \cdot$ Katharina Paulhart $^{1}$ \\ Received: 8 November 2015 / Accepted: 13 November 2015 / Published online: 21 November 2015 \\ (C) The Author(s) 2015. This article is published with open access at Springerlink.com
}

\begin{abstract}
The text deals with a policy instrument developed by the European Union, namely the so called Mobility Partnerships. Framed within the "Global Approach to Migration and Mobility" of the EU, this rather new concept (1) is promoting new ways of legal migration, (2) is combating irregular migration and human trafficking, and (3) strengthening the nexus between migration and development. In the end, a "Win-Win-Win" situation should be established for all the parties being involved: Migrants, originand destination countries. What characterizes the partnerships in the first place is flexibility: on the one hand the optional involvement by EUmember states and on the other the wide and flexible range of contents. Signatories are the EU Commission, participating member states and in each declaration one third state. For the moment, partnerships with following countries do exist: Cape Verde, Moldova, Armenia, Georgia, Azerbaijan, Morocco and Tunisia. The text gives a general introduction and analysis on the EU Mobility Partnerships plus the specific case of the Mobility Partnership with Moldova. Three essential research questions are raised to be answered: (1) First, how and with what purpose are different aspects (migration, security, development, labour market and economy) linked within the Mobility Partnerships? (2) Second, which interests and actors underlie the partnerships? (3) And third, what perception of "development" is accompanied by the new policy instrument? These questions are answered through the methodological approach of the hermeneutic data analysis and the theory of the critical border- and migrationregime.
\end{abstract}

Stefan Brocza

stefan.brocza@univie.ac.at; stefan.brocza@sbg.ac.at

1 Department of Geography and Geology, Social and Economic Geography, University of Salzburg, Salzburg, Austria
Keywords Mobility partnerships · European Union · Externalization $\cdot$ Migration control $\cdot$ Moldova

\section{Introduction}

One glimpse at any European newspaper edited lately makes the reader gain the impression that crises and problems keep getting bigger and even more. A lot of negative developments emerging simultaneously started to show their effects on Europe: The Economic Crisis leading to the maybe worst labor market expectations for a long time and not just recently, but even closer to the core of Europe now, the number of people seeking for asylum has been escalating enormously. The tragic images of boat people trying to reach Europe's coasts match the scenes along some European internal borders, the overextension of European governments disclose their cluelessness concerning the future. The latest idea coming up in one member state after the other is demarcating themselves through fences, which does without question make us think back in European history when borderlines were clearly drawn like that.

During the last decade the external dimension of the European Union's migration policy has shifted between an increasing isolation and a selective opening of the labor markets for specific groups of profession and qualification. Especially "external shocks" like tragic events as described above often led to reacting through new political initiatives and strategies [7: 284].

One strategy, which was implemented as a consequence first in 2008 was the EU (European Union) concept of Mobility Partnership. Its core idea is not any more part of the credo of closing any European border, but is contracting partnerships with third countries to improve the controlling of migration and at the same time offering third country citizens to enter legally on purpose of working in the EU. 
Hereby, labor shortage shall be compensated, the pressure of immigrants reduced and the countries of origin supported. In 2008 two pilot-partnerships started with Cape Verde and Moldova. Meanwhile five more partnerships were amended with the following countries: Armenia, Georgia, Azerbaijan, Morocco and Tunisia.

As suggested earlier, different fields of policy are affected by the concept of Mobility Partnerships, e.g., migration policy, external security, labor market policy and development policy. Given this overview it can be described as a multidimensional concept. Presuming that the EU is not going into total isolation after the most recent events and is going to stick to the idea of the Mobility Partnerships: is there a chance that this multidimensional concept might be part of a solution to the eclectic and multilayered problems Europe is going to face in the upcoming years?

In the following this question is going to be dealt with, through a general introduction and analysis on the EU Mobility Partnerships plus the specific case of the Mobility Partnership with Moldova. As it was one of the first partnerships started, first reports and assessments on the experiences and effects are already available.

\section{The concept of mobility partnerships}

The interweaving of the two discourses of migration and development, the so-called migration- and development-nexus, is a long discussed topic. Castles [3], for example, deals with the question whether migration or development has come first. Generally scientists agree that both phenomena are part of one process: The higher the "development" (in a socio-economical sense) the more are the options of mobility, which stimulate migration in turn. It is exactly this understanding that did not quite reach the public and politics. What's dominating is the so called "root-causes"-approach which indicates migration as a simple consequence of causes in origin countries, which again suggests to reduce migration by fighting its roots, e.g., diminishing poverty [3:1].

Influenced by this positive connoted nexus the EU designed a new concept as regards migration policy as well: mobility partnerships. According to the proponents of this strategy the advantage and goal lie in a "triple-win"-situation for migrants, partner countries and EU member states [2: 5].

The specific design of each partnership might differentiate. From EU's part it applies to each country whether it wants to participate in mobility partnerships. Regarding the content, the focus areas and emphasis might vary as well [2: 16]. The past relation between the EU and the third country play an important role when designing the country's specific mobility partnership because the agreement should operate in addition to existing approaches, agreements and cooperation [2:24]. Therefore the
European Commission emphasizes the individuality of each agreement combining the partner's specific needs and the EU's goals. Among the possible commitments from third countries are readmission (of their own citizens and transit migrants), an initiative to prevent irregular migration by improving border control, combating cheat and forgery, preventing trafficking in human beings and supporting of productive occupation and humane working conditions. To meet these and commitments alike the EU and potential participating member states hold out the prospect of financial and technical support [5: 4-5].

The legal character of mobility partnerships is multilayered, as the EU and others carry out some responsibilities by the member states. The compatibility of the relation built between the member states and third countries to the existing legal and political frame of the EU remains the uppermost priority though [5: 3].

The mobility partnerships are legally registered in forms of political declarations between the participants. Therefore the agreements are legally not binding [4: 4].

Intentionally the partnerships shall not be rigid, but flexible, "living documents". The agreement is for example always open for new participants. Thus the flexibility is a call upon the participating actors as well to adjust the partnership as concerns changes and new requirements [2: 16, 22].

The idea drawn in published communications on mobility partnerships and circular migration do not just show that mobility partnerships influence different policy areas but disclose as well that policy areas are interwoven with each other. Hence it clearly follows the idea of a global and holistic approach. Roughly spoken there can be elaborated three central links between different policy fields, which are presented in the following.

\section{Development policy and security policy}

The European Commission emphasizes regularly the importance of supporting ways of legal migration to counteract "illegal" migration. According to this understanding, "illegal" migration reduces automatically in favor of legal migration because of possibilities to migrate regularly more easily. This idea of the capability of intervening and controlling migration processes corresponds to the prevalent image in EU politics on what is effective migration policy. Whereas this link is not approved empirically, Angenendt [1] points out that

[...]individuals who are willing to participate in legal immigration programs could be prevented in engaging in dangerous attempts at illegal immigration because they would have the reasonable hope of actually reaching their goal, possibly with some delay but with a much lower risk.[1: 3$]$ 
Measures which are suggested by the Commission in the communication on mobility partnerships are on the one hand the support of readmission agreements and on the other hand the improvement of possibilities of legal migration for third country citizens - which are maybe connected with the greatest success for both parties in the negotiations. Different forms of a favored treatment in the case of legal migration can be agreed on. Firstly, the Commission introduces the possibilities of employment rates, which could be surveyed due to the needs of European labor markets to match between offer and demand. Secondly, improvements for the admission of migrants of specific categories (e.g., professions) are recommended. Part of this might be as well the admission for studies and education [5: 5-6].

Schwiertz [9] perceives in the opening of new legal migration paths a legitimating by the EU to enlarge and intensify its control [9: 153]. The connection between "legal"and "illegal"migration which is established by the Commission, is to be understood as a link between aspects of development policy (mostly according to an economical understanding of profits in the sense of money but as well gain of knowledge, which can be achieved by citizens of partner countries during temporary migration) and goals of security and migration policy for EU member states, which are hoping for an improvement in the control of migration.

\section{Development policy and labor market policy}

Further interwoven with the topic of Visa is the commitment of EU member states to short-term visa, a part of the dogma of circular migration, which is pursued by the EU and shall prevent from long-term emigration of highly qualified people, hence from brain drain. Improvements are planned on two levels: Firstly, on the operational level where consular cooperation shall be revised, especially to be capable to pursue the strived flexibility regarding the validity and duration of visa which should serve as reward for those migrants who are acting compliant to the rules. Secondly, on the systematic level to ensure specific professions easier access in general [5: 7-8].

Through the promotion of short term migration but as well the inclusion of study and educational migration and the support in re-migration, a development political component is built which is linked at the same time to EU labor market aspects. The EU has been striving for already some time to recruit highly qualified migrants. Educational experience made in Europe shall serve as a bond for a future return. Besides, the combination of an ageing society and a shrinking number of people apt to work - this has drastic effects for Europe. These facts put pressure upon the pension-, healthand social system like on economic entities (tax system, economic growth) [8: 647]. "Without migration, the EU will not be able to meet future labor and skills shortages." [8: 648]
Gaps and occupational shortages on European labor markets might be filled and reduced through short term or circular migration without committing on the long run - a solution that is probably easier represented in front of "the" public.

\section{Human rights policy and security policy}

The basic idea of an advance in regulating migration is concerned, besides the filling of gaps on European labor markets, with the desire to control the movements and flows of migrants. So the commitment on the third countries' part as to more border control, security and containment of irregular migrants takes in a crucial position within the partnership agreements [2: 18-19].

The third link established in the commission's declaration is constituted exactly in this context of the improvement of border administrations. For partner countries this is presented as an obligation to reduce security risks related to international migration [5: 5]. A part from risks taken when migrating irregularly a specific focus is set on combating trafficking on human beings. Here the commission emphasizes everybody's right on international protection, which has to be assured for those who need it. Therefore financial and technical assistance is granted so that third countries are able to fulfill these obligations in protecting [5: 4-5].

So it is shown that human rights aspects have found their way into the agreements and are integrated in security policy by obligations on strengthening borders, border controls or the improvement of travel documents that shall apparently protect all the parties concerned [5: 4-5].

Not least does the commission recognize that "uncontrolled" immigration or transmigration has become a problem for (potential) partner countries likewise, which is why they might be welcoming security implications to strengthen their own borders anyway [9: 175].

\section{EU mobility partnership with Moldova}

After the general overview and analysis of the EU mobility partnerships given above, the mobility partnership with Moldova as one of the partnerships with the longest experience in this program is being reviewed in this chapter.

In the case of the Moldovan Mobility Partnership, the following EU member states signed their participation in May 2008: the Republic of Bulgaria, the Republic of Cyprus, the Czech Republic, the French Republic, the Hellenic Republic, the Federal Republic of Germany, the Republic of Hungary, the Italian Republic, the Republic of Lithuania, the Republic of Poland, the Portuguese Republic, Romania, the Republic of Slovenia, the Slovak Republic and the Kingdom of Sweden [4: 1]. 
Until now, there is just one report evaluating the Moldovan mobility partnership available. Finished in April 2012, it evaluates the period between the launch of the mobility partnership in June 2008 until the date of expiry in 2011 [6: 2]. Keeping in mind that 4 years have passed since, we have to assume these results as a certain trend but not as corresponding to the reality of dates. The content of the report is based on questionnaires sent to all the institutions of the Republic of Moldova involved in the implementation, to the participating EU Member States, to international organizations and migrant organizations. Background information was mainly given through statistical databases such as Eurostat and the draft back of the Extended Migration Profile [6: 2].

An important remark is given right at the start, emphasizing that data and assessment about developments cannot be linked neatly and solely to the programs and activities of the Mobility Partnership. It cannot be asserted to what extent surrounding factors were as well influencing the developments [6:2].

The Mobility Partnerships are part of the EU's Global Approach to Migration (GAM) and later complemented by Mobility (GAMM). The main objectives of the Partnerships were therefore primarily matched with the three, respectively later four, pillars of the Global Approach, which are the following: legal migration, migration and development, the fight against irregular migration and international protection.

With a view to the present evaluation data collection, monitoring is still outlined to be a future goal, although already mentioned as one objective in 2008. In general a lot of indicators cannot be used clearly because of the lack of data not just from before 2008 but as well in 2012 [6: 21].

\section{Legal migration}

The pillar of "Legal Migration" comprises probably the most relevant projects for Moldova as part of the agreement with the European Union. Already in 2007, 1 year before the Mobility Partnership was amended, two agreements were signed between the Republic of Moldova and the European Union: one facilitating the issues of visa for Moldovan citizens, the other about readmission. These agreements build Together with the Mobility Partnership these agreements build the newest framework on legal migration between Moldova and the European Union. Thus one objective expressed in the declaration on the Partnership deals with an improved access to the Member States' labor markets and the information about the possibilities of the European labor market in general. In consequence of the visa facilitation agreement a visa application center was opened. In order to inform potential migrants, actions were taken through websites, such as the publication of country guides, job fairs, training sessions or study visits. Although it is difficult to measure the level of information for migrants, a number of actions have been set in this field [6: 27-30].
However, the prevailing opinion on offers in the sector of labor migration possibilities, which is given in the Evaluation Report, including circular and temporary forms, is less positive and "[...] viewed [...] as fairly stagnant." [6: 24] From the EU Member States' point of view the influence of the economic crisis, which reached a climax when the Partnership with Moldova was concluded, is to blame for not having created more possibilities to be more active in offering more possibilities on mobility [6:24].

Eventually until 2012 small-scale projects were conducted as pilot projects, from which, in accordance to the Report, only few individuals have benefitted from the effort made in the section of circular and temporary migration [6:25]. Connected to the topic of mobility opportunities for Moldovan citizens is the intention of improving the "Social protection for migrants and the conclusion of social security benefit transfer agreements".[6:29] This work field has made significant progress in the means of numbers to transfer social security benefits back and forth between Moldova and EU host countries, but viable solutions for the more targeted group of short time migrants are still missing [6:29]. So the evaluators conclude that," it is worrying that the issue of social protection for migrants, which is very important to MD [Moldovan] authorities, non-state respondents and the MD migrant organizations, receives relatively little attention by some EU MS [member state] that host significant populations of MD [Moldovan] migrants." [6: 30]

\section{Migration and development}

There are certain phenomena related to the action of migration, which take place either in the outgoing or incoming country: brain drain and brain waste. Through measures taken within the Mobility Partnership both of them should be prevented. The first term means that mostly people with high potential and specific qualification emigrate to have better opportunities of working and earning abroad. Clearly, there are negative effects produced on their cities and countries of origin, if specifically those skilled workers and highly qualified workforces are missing, who are often quite important for developments in the home society (e.g., medicines, scientists, etc.). Brain waste, on the other hand, describes the phenomenon of "de-qualification" of people conducting jobs below their qualification in a lowskill sector abroad, not making use of their skills and in the course of time even losing them. Both the phenomena can be observed during the migration term, but as well on the return [6: 37]. Brain drain and brain waste are hard to quantify since the data recording on education or skills has not been given much of a priority in the past. However, as the awareness on the importance of skills and qualification is rising, data collecting in the field is on the rise as well. According to the evaluation report, EU members and 
participants in the partnership do not see the emigration of knowledge, its effect on Moldova and the structure of its economy as their responsibility [6: $35-36]$, so to say as "[...] beyond the sphere of migration policy." [6:36] Therefore, corresponding to the evaluators only few activities were accomplished in preventing brain drain-with some exceptions such as study visits and returning programs [6:35-36]. Whereas in the prevention of brain waste an initiative on skills validation was started for returning migrants and concepts were formed on the level of recognition of qualification. The report definitely highlights the impulse given by the mobility partnership addressing the questions of validation and description of different types of learning and the recognition of qualifications [6:38].

When speaking of the correlation of Migration and Development, the importance of remittances is mostly mentioned as a key impact on countries of the migrants' origin. Therefore remittances are as well an objective to be developed within the partnership. Until 2012 Member States had only one initiative on transferring money, whereas generally remittances through official channels are proven to be on the rise [6: 41-42].

Another objective within the pillar of Migration and Development is the problem of "children and elderly left behind/ without care due to migration", which rose to a worrying level. Emphasis was set on measures providing the children with community activities and psychological support. The actions assessment concludes negatively as it is stated that a real improvement can only be achieved by increasing options of mobility. However, the problem itself gained attention in Moldova and Europe [6:32].

\section{Fight against irregular migration}

Objectives and actions in this pillar implicate the modernization and professionalization of the Moldovan border management [6: 45] and setting new standards in the field of document security. Within the next years biometric passports shall be in use exclusively [6: 47]. Yet, this enormous progress is facing criticism as well:

However, there may be some tension between increasing document security and fostering mobility. Given the low average income in MD, it cannot be ruled out that the increased price of a passport acts as an impediment to mobility [6:48].

The strengthening of the readmission agreement, which was amended in the year 2007 represented by far, the most lauded content by the respondents of the questionnaire. Projects supporting the implementation of the agreement were set up. Nominally it was already clear back then that the Readmission Agreement had been effective [6: 49-50]. The situation concerning the reduction of irregular migration and the trafficking in human beings was pictured likewise. Finally it is stressed that although some partners were on planning further initiatives, the system in the field of anti-trafficking is already very complex, which is why a doubled structure is feared [6:50-55].

\section{International protection}

As far as asylum and international protection are concerned, projects were planned on improving the Moldovan asylum system because Moldova does not quite seem experienced in this area, as it does not appear as a main goal for asylum seekers, although the number of asylum seekers in Moldova is on the rise. The actions, which have been taken, were mostly on the operational level, like on handling applications. Although progress has taken place, there remains still a lot of work to be done. The major challenge for the upcoming years is seen in the integration of migrants [6:25-30].

Primarily there is a concluding impression given, that the EU-Moldova cooperation in the framework of the mobility partnership is a very successful one, that interests were matched very well and that a strengthening in the fields of mobility and migration has taken place. There is a big consensus on improvements in the sector of security and fight against irregular migration (the readmission and return have been facilitated, the border security has been strengthened, the asylum system and document security have been improved), although the evaluators' note that this success can be attributed probably more to developments outside the framework of the Mobility Partnership. Clearly, there is some more effort to make in enhancing the possibility of mobility and visa facilitation, as there are yet very few initiatives to foster circular migration between the EU and Moldova and those existing are being conducted in pilot phases on a small scale. The same applies to the area of Migration and Development in which a lot of challenges could not be met yet either. This means, further, that positive effects on migrants and potential migrants themselves were quite scarce and could have been targeted better [6: 55]. The official 2012 Evaluation Report concludes as following:

While there is still a predominance of security-centered policies aimed at fighting irregular migration, there has been progress in giving more weight to migration and development, and, to a somewhat lesser extent, in facilitating legal migration. [6:56]

Another finding of the report underlines that for pursuing further concepts of temporary migration political and economic measures are necessary, which are seen far beyond the reach of migration policies [6:56]. 


\section{Conclusion}

The discussion of the variety of measures taken in order to establish mobility partnerships has shown the farreaching effects and consequences of single agreements and thus the introductory question if Mobility Partnerships can be a possible future instrument to the multidimensional challenges Europe is facing cannot be answered in one sentence. It is preferable to submit a number of sub-answers to cover all the complex aspects this question brings along. Primarily, there has to be given a summary why exactly the concept of mobility partnership could serve as a possible instrument in handling the current situation successfully. In the following I would like to go more into detail as to whether mobility partnerships are even intended to be part of a possible solution of Europe's situation and if, or if not, by whom. These sub-answers will ultimately lead us to a realistic estimation of the factual situation.

The prior assumption in this text implicated that the EU uses the migration and development nexus together with the call for more political coherence as an opportunity to affect and relate various policy fields like migration, development, labor market, economy and security with each other by the establishing of mobility partnerships.

However, it was found that the above-mentioned areas of policy were connected with each other in a way that finally put the implications concerned with security aspects into a dominant and central place within the partnership. At the same time the EU is able to design a selective immigration policy, on its own condition, adjusted to the European labor markets. Concessions on actions in the field of development politics are therefore just to be formed in between the saturated anchor points of security and labor market policy of the EU actors. Nonetheless, these development political concessions are to be valued as strategically crucial components in the making and negotiating of the mobility partnerships. It became even apparent that these relations of diverse interests are the key of cooperation and therefore the programs basis and success of mobility partnerships.

According to the theoretical approach of the regime theory, as well used in the theory of the border- and migration regime, a regime, like the present European migration regime, is shaped by various actors and interests and not by just one linear idea. The same applies to the institution of the $\mathrm{EU}$, which is not just running by itself but primarily under the member states' conditions and among those, probably under the conditions of the strongest member states. Therefore, its organization cannot be qualified as being homogenous, but a constitution of related institutions and preeminently the (strongest) member states governments themselves, who are in the decision making of the European asylum- and migration policy.
As regards the question on the intention of mobility partnerships in Europe's future it is quite clear that the European migration policy, following the argumentation and analysis described earlier in the text, represents a very restrictive regime. The intention of the instrument of mobility partnerships, of the strategy of co-operations through relating different interests, can be valued in first place to enlarge its migration regime/sphere of influence and to externalize Europe's external borders. Through partnerships with Moldova and alike concrete steps have been taken to integrate these countries into the European migration regime - future will show to which grade and intensity. However, this assumption is not contradictory to the fact that these initiatives might have a positive development political effect, though these effects are to be valued of a secondary value.

Recapitulating the preceding paragraphs, it is clearly stated that the prior intention of the mobility partnerships, despite their multidimensional character, is not solving the considerable number of crises Europe is dealing with, but serving mostly the goal of externalizing its borders as a solution to upcoming problems. But even if there were different purposes underlying, could the mobility partnership be a possible future instrument to encounter the multiple European crises?

Mainly through the report of the Moldovan mobility partnership it was outlined that this strategy is no universal remedy. Conditions in partner countries were observed, which were seen as "[...] beyond the sphere of migration policy [...]" [6:36], but often fundamental for the functioning of the partnership. Still, according to the Moldovan experiences, even in the existing framework, success would have been possible to a greater extent.

Open Access This article is distributed under the terms of the Creative Commons Attribution 4.0 International License (http:// creativecommons.org/licenses/by/4.0/), which permits unrestricted use, distribution, and reproduction in any medium, provided you give appropriate credit to the original author(s) and the source, provide a link to the Creative Commons license, and indicate if changes were made.

\section{References}

1. Angenendt S (2007) Circular Migration. A sustainable concept for migration policy? Stiftung Wissenschaft und Politik (Swp) Comments http://swp-berlin.org/fileadmin/contents/products/ comments/2007C11_adt_ks.pdf. Accessed 08 Nov 2015

2. Angenendt S (2012) Migration, Mobilität und Entwicklung. EU Mobilitätspartnerschaften als Instrument der Entwicklungszusammenarbeit. Stiftung Wissenschaft und Politik (SWP): Berlin. http://www.swp-berlin.org/fileadmin/contents/ products/studien/2012 S25 adt.pdf. Accessed 08 Nov 2015

3. Castles S (2008) Development and Migration - Migration and Development: What comes first? Presentation at the Social Science Research Council Conference "Migration and Development: Future Directions for Research and Policy http://www.imi.ox.ac.uk/pdfs/ 
S\%20Castles\%20Mig\%20and\%20Dev\%20for\%20SSRC\% 20April\%2008.pdf. Accessed 08 Nov 2015

4. Council of the European Union (2007) Joint declaration on a mobility partnership between the european union and the republic of moldova. 21.05. 2008. Doc. 9460/08

5. European Commission (2007) communication from the commission to the european parliament, the council, the european economic and social committee and the committee of the regions on circular migration and mobility partnerships between the European Union and third countries ircular Migration, COM (2007) 248 final., Brussels, 16.5.2007

6. Ministry of Foreign Affairs and European Integration of the Republic of Moldova (2012) The European Union-Republic of Moldova
Mobility Partnership 2008-2011: Evaluation Report. http://www. $\mathrm{mfa}$.gov.md/img/docs/eu-moldova-mobility-partnership-evaluation. pdf. Accessed 02 Nov 2015

7. Papagianni G (2013) Forging an external EU migration policy: from externalisation of border management to a comprehensive policy? Eur J Migr Law 15(3):283-299

8. Population Council (2010) Documents. Project Europe 2030 on the challenging of Demography. Population and Development Review, Nr. 36, Ausgabe 3, 647-650

9. Schwiertz H (2011) Foucault an der Grenze. Mobilitätspartnerschaften als Strategie des europäischen Migrationsregimes. LIT Verlag, Münster 